\title{
An in situ pulse light fluorometer for chlorophyll determination as a monitor for vertical and horizontal phytoplankton distribution in lakes*
}

\author{
Urs Uehlinger \\ Institute of Aquatic Sciences (EAWAG), Swiss Federal Institute of \\ Technology (ETH), CH-8600 Dübendorf, Switzerland
}

\begin{abstract}
Methodological problems with in vivo fluorescence (IVF) measurement using an in situ pulse light fluorometer were investigated in order to validate this method for monitoring the vertical and horizontal chlorophyll $a$ (chl. $a$ ) distribution in lakes. The correlation between chl. $a$ and IVF was poor in the upper epilimnion $(0-5 \mathrm{~m})$ of a mesotrophic lake. The IVF of algal cultures and natural phytoplankton is very sensitive to changes in the light environment. The response of the IVF to rapid light fluctuations depends on the amplitude of the light intensity and the light conditions to which the algae were exposed before the onset of light fluctuations. The variability of the ratio IVF:chl. $a$ concentration makes a permanent calibration of the IVF against chl. a necessary.
\end{abstract}

\section{Introduction}

The in vivo chlorophyll $a$ fluorescence (IVF) technique can be used for monitoring the vertical and horizontal distribution of chlorophyll $a$ (chl. $a$ ) and consequently phytoplankton. In contrast to profiles obtained by discrete sampling, the exact position of chlorophyll maxima can be determined (Berman, 1972).

In general, flow-through fluorometers have been used to measure the IVF of chl. $a$ (e.g., Lorenzen, 1966; Kiefer, 1973a; Setser et al., 1982). Pulse light fluorometers (Früngel and Koch, 1976, 1980) combine fast sampling rates with relatively high resolution. In spite of these advantages, the application of pulse-light fluorometers for in situ chl. $a$ detection has, with few exceptions (Herman and Denman, 1977; Nusch and Koppe, 1981), been ignored so far.

It was the aim of this work to examine methodological problems of pulse light fluorometric measurements and to evaluate the suitability of this method for monitoring vertical and horizontal chl. $a$ distribution in lakes.

\section{Methods}

IVF measurements were undertaken using a 'Variosens II' in situ pulse light fluorometer (manufacturer: Impulsphysik GmbH, 2000 Hamburg 56, W.Germany). The pulse frequency of the xenon flash-lights is $10 \mathrm{~Hz}$ with a duration of $\sim 10 \mu \mathrm{s}$. The projector filter has a wide optical band $(400-520 \mathrm{~nm})$, the receiver bandpass filter peaks at $680 \mathrm{~nm}$ with a band width of $30 \mathrm{~nm}$. The instrument is equipped with a pressure sensor. IVF profiles were continuously plotted on a XY-recorder. An acrylic glass cuvette allowed the measurement of the IVF in the laboratory. The influence of 3-(3,4-di-

*This paper is the result of a study made at the Group for Aquatic Primary Productivity (GAP), Second International Workshop held at the National Oceanographic Institute, Haifa, Israel in April - May 1984. 
chlorophenyl)-1,1-dimethyl-urea (DCMU) on the IVF of either phytoplankton or cultured algae was studied by addition of a supersaturated solution of DCMU (final concentration $10 \mu \mathrm{mol}$ ) to the sample.

In order to detect the influence of particulate scattering on IVF measurements, suspensions of garnet, mean size 3.85 and $12 \mu \mathrm{m}$, were prepared.

Field data were collected at two stations in the mesotrophic Lake Lucerne (Kreuztrichter, Kastanienbaum), and some measurements were performed in limnocorrals suspended in the same lake (Uehlinger et al., 1984). Water samples for chlorophyll measurements were taken at different depths with a Friedinger bottle, and $500-1000 \mathrm{ml}$ of each sample were filtered on Whatman $\mathrm{GF} / \mathrm{C}$ glass fiber filters. After grinding with acetone (90\%), chl. $a$ was determined according to APHA (1975) and SCOR-UNESCO (1969). Both methods gave similar results, but greater variations were evident in the APHA procedure, and hence, this was rejected.

Relative underwater light intensity was measured with an integrating quantum-meter (LI 188 B, quantum sensor LI-193 SB, LI-COR inc. Lincoln, Nebraska, USA). The photosynthetic active radiation (PAR) was continuously monitored using a LI-COR quantum sensor (LI-190 S) and printing integrator (LI-550).

The green alga Chlamydomonas reinhardii Danegard (No. 11-32a, algae collection, University of Göttingen, W.Germany) was cultured in phosphate-limited chemostats at constant light and temperature, $430 \mu \mathrm{E} \mathrm{m}^{-2} \mathrm{~s}^{-1}$ and $22.5^{\circ} \mathrm{C}$ respectively (Hirsbrunner, 1981). The phosphate concentration of the $Z$ medium (Staub, 1961) was $90 \mu \mathrm{g}$ $\mathrm{P}^{-1}$.

\section{Results}

Figure 1a shows the effect of particle scattering. Maximum signals of 10.6 and $25 \mathrm{mV}$ were recorded with relatively high particle concentrations $\left(10^{8}-10^{9} 1^{-1}\right)$ for $12 \mu \mathrm{m}$ and $3.85 \mu \mathrm{m}$-sized particles, whereas the IVF of $2.4 \times 10^{8}$ Chlamydomonas cells $1^{-1}$ was $469.9 \mathrm{mV}$. Thus, the effect of scattering (which depends on the particle size) is about two orders of magnitude smaller than the IVF of algae of similar size. Larger particles were not tested because of methodological problems. Self-shading seems to be more important as shown by the relation between IVF and chl. $a$ concentration (Figure 1b). In different dilutions of Chlamydomonas cultures and net plankton suspensions, the deviation from linearity increases with increasing chlorophyll concentration. Since in Lake Lucerne the chl. $a$ concentrations were generally $<15 \mathrm{mg} \mathrm{m}^{-3}$ and only once exceeded $20 \mathrm{mg} \mathrm{m}^{-3}$, any underestimation of IVF was $<8 \%$.

With a pulse light fluorometer, in situ measurements of IVF take place at natural ambient light conditions. This differs from field adapted laboratory instruments with flow-through systems, where the fluorescence is measured in darkness. The IVF of natural phytoplankton increased $\sim 50 \%$ within 2 min after light exclusion (Figure 2). The light change and time delay between sampling and measurement when sampling with a hose decreases the disturbing effect of photoinhibition of the IVF of a plankton sample measured with a flow-through fluorometer.

The determination of the IVF of chl. $a$ may also be affected by 'soluble' fluorescence originating from humic substances (Carlson and Shapiro, 1981). The determination of chl. $a$ may be underestimated by loss of picoplankton which pass the GF/C glass fiber 

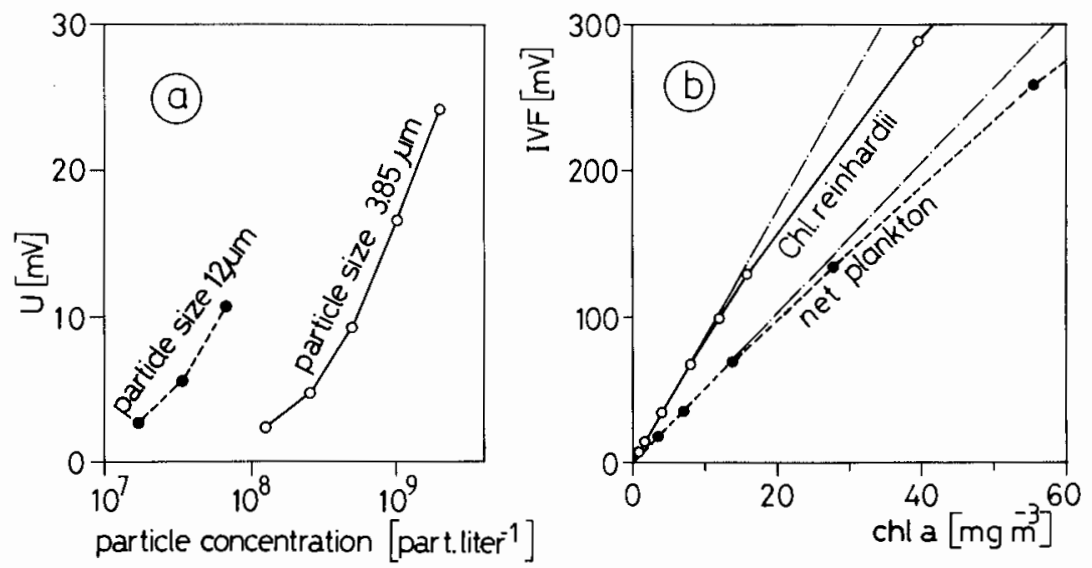

Fig. 1. Effect of particle scattering and self-shading on the measurement of IVF. (a) Relationship between particle concentration and scattering. The light scattered by particles yields the signal $U$. (b) Relationship between chl. $a$ and IVF. Different dilutions of Chlamydomonas culture and net plankton samples (dominated by Fragilaria crotonensis and Melosira sp.) with phosphorus free Z medium and filtered lake water, respectively.

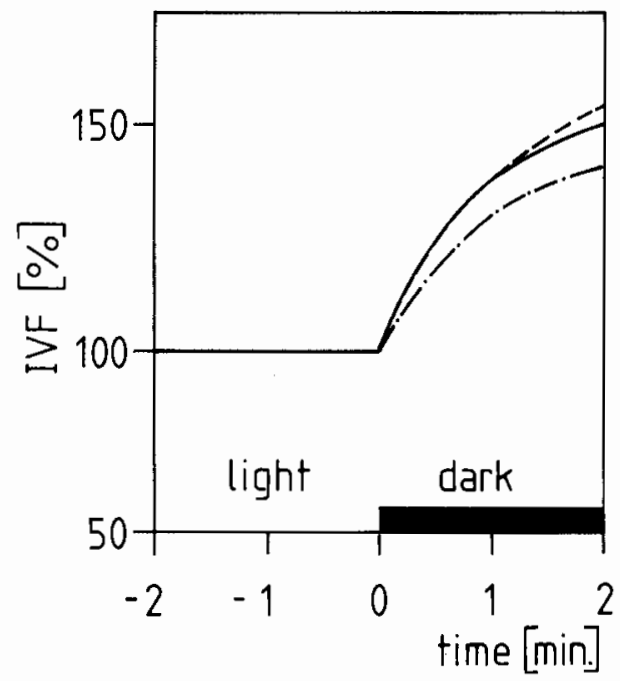

Fig. 2. The influence of ambient light on the measurement of the IVF of natural phytoplankton. Before darkening the samples were exposed to daylight (mean light intensity $800-1200 \mu \mathrm{E} \mathrm{m}^{-2} \mathrm{~s}^{-1}$ ) for $25-80 \mathrm{~min}$.

filters. Data from Lake Lucerne showed a mean fluorescence of the GF/C filtrate of $1.94 \pm 0.38 \mathrm{mV}(\mathrm{n}=34)$ with constant values over time and depth. For the subsequent calculation of $\mathrm{R}$, the ratio IVF:chl. $a$ concentration, this mean soluble fluorescence was subtracted from the measured IVF as a correction. Few measurements showed that between $75-100 \%$ of this soluble fluorescence passed $0.45 \mu \mathrm{m}$ pore size membrane filters. 

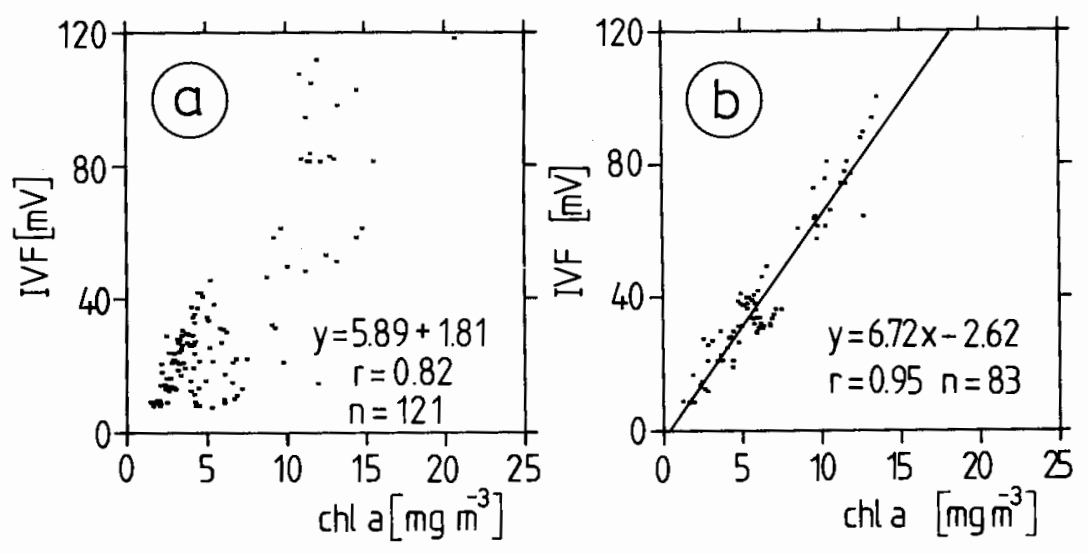

Fig. 3. Relationship between chl. $a$ IVF (combined data from Lake Lucerne, March 1983 - April 1984). (a) Values from $0-5 \mathrm{~m}$. (b) Values from $>5-15 \mathrm{~m}$.

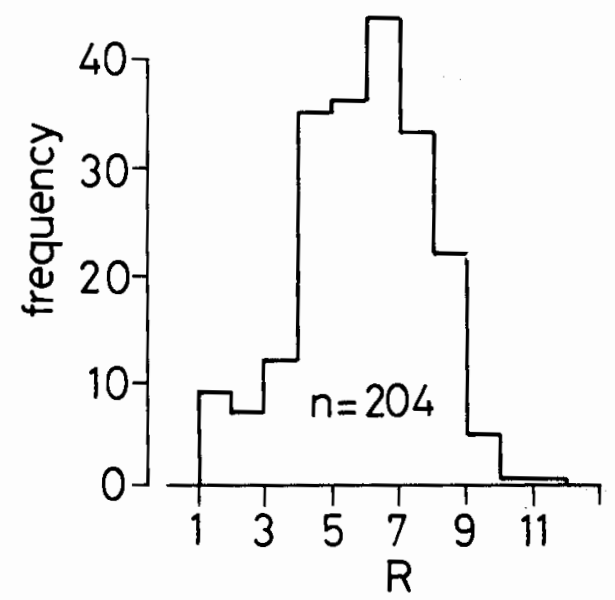

Fig. 4. Frequency distribution of R (combined data from Lake Lucerne, March 1983-April 1984).

The correlation between chl. a concentration and IVF has been calculated for two depth ranges (Figure 3). At depths $>5 \mathrm{~m}$ the correlation coefficient $r$ indicates that $>90 \%$ of the variation in IVF can be explained by changes in chl. $a$ concentration. However, in the upper epilimnion $(0-5 \mathrm{~m})$ only $67 \%$ of the variation was due to changes in chl, a. The corresponding coefficients of variation ( $\sigma /$ mean) of R were 20 and $39 \%$, respectively. Several factors such as light (Kiefer, 1973a; Loftus and Seliger, 1975), species composition (Heaney, 1978) and nutrient stress (Kiefer, 1973b; Smith, 1983) can account for the variation of $\mathrm{R}$ with a broad range from 1.2 to 11.5 during the annual cycle in Lake Lucerne (Figure 4). In addition, at low chl. $a$ concentrations ( $<3 \mathrm{mg}$ $\mathrm{m}^{-3}$ ) errors in the photometric chl. $a$ determination and the IVF measurement may contribute $20 \%$ and more in the variation of $R$.

Typical vertical profiles of chl. $a$, IVF and $\mathrm{R}$ are shown in Figure 5. At low light 

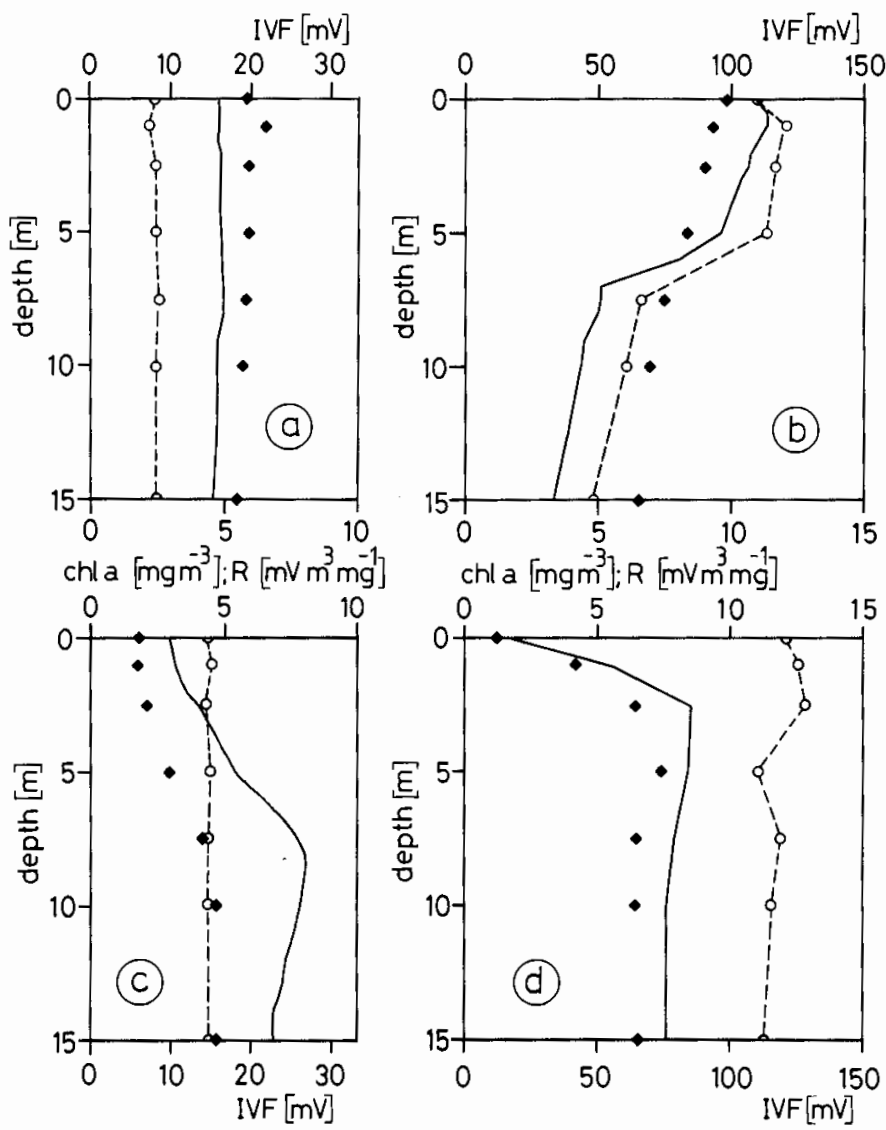

Fig. 5. Vertical profiles of chl. $a(\mathrm{O}-\mathrm{O})$, IVF $\left(\longrightarrow\right.$ and $\mathrm{R}(\bullet)$. (a) 7 November $1983 \mathrm{I}_{0}=$ $54 \mu \mathrm{E} \mathrm{m}^{-2} \mathrm{~s}^{-1}$, (b) 4 May $1983 \mathrm{I}_{\mathrm{o}}=173 \mu \mathrm{E} \mathrm{m}^{-2} \mathrm{~s}^{-1}$, (c) 10 February $1984 \mathrm{I}_{\mathrm{o}}=657 \mu \mathrm{E} \mathrm{m} \mathrm{m}^{-2} \mathrm{~s}^{-1}$, (d) 22 April $1983 \mathrm{I}_{\mathrm{o}}=1086 \mu \mathrm{E} \mathrm{m}^{-2} \mathrm{~s}^{-1} \cdot \mathrm{I}_{\mathrm{o}}=$ light intensity at the lake surface.

intensities, IVF and chl. $a$ correlate well (Figure 5a and 5b). However, on sunny days the IVF is strongly inhibited close to the surface (Figure $5 \mathrm{c}$ and $5 \mathrm{~d}$ ). The diurnal change in light which is dependent on the weather conditions has a strong influence on the IVF (Figure 6). In a limnocorral experiment on 1 June 1983, photoinhibition could be detected down to $4 \mathrm{~m}$, an effect which would probably have been more distinct without the shading of the limnocorral wail. On 1 July 1983 no photoinhibition could be observed, when the light intensity decreased a few hours after sunrise. When phytoplankton from Lake Lucerne were adapted to darkness for $2.5 \mathrm{~h}$ before light exposure, the IVF decreased rapidly within $15 \mathrm{~min}$ to an almost constant level. However, when such light-adapted phytoplankton were transferred to darkness and left there, at least $2 \mathrm{~h}$ were required to reach a maximum constant IVF. Because the process of inhibition is faster than the process of recovery, the diurnal change of IVF is asymmetric and slight hysteresis can be observed (Figure 7).

In Lake Lucerne the minimum light intensity where photoinhibition could appear was 

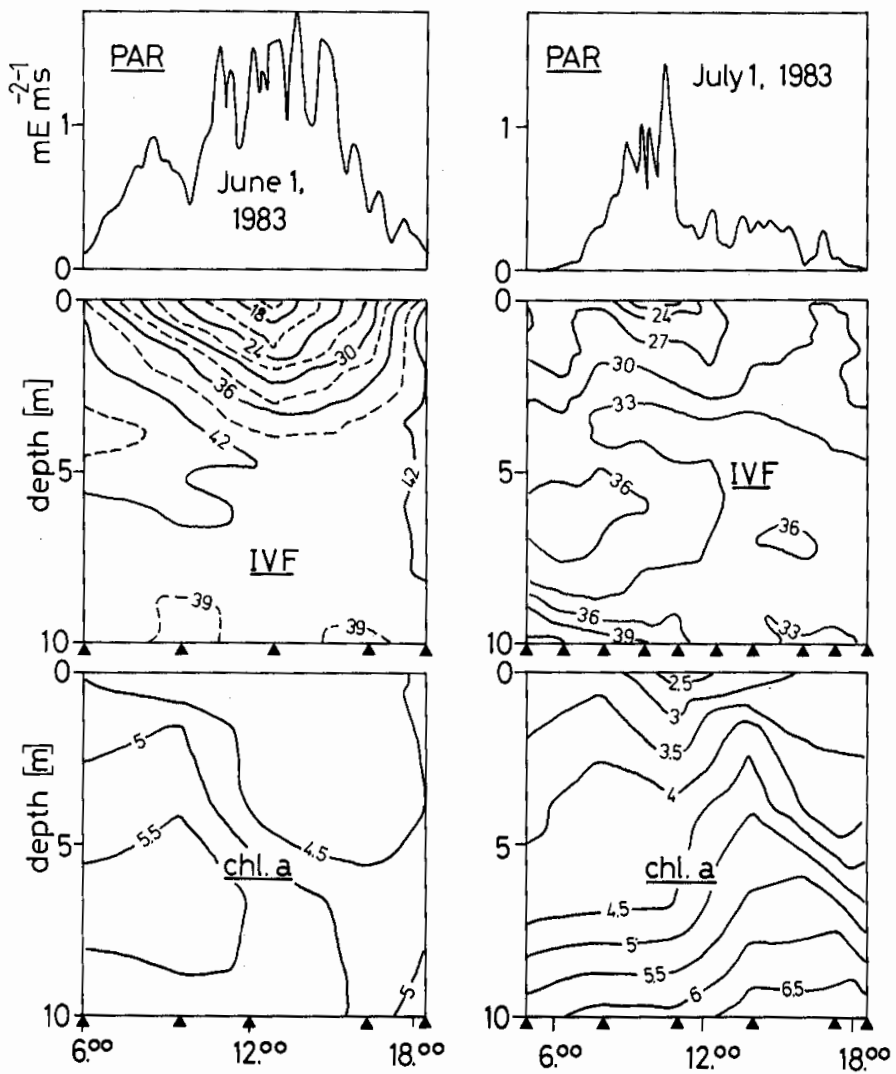

Fig. 6. Diurnal changes in light intensity (PAR $\left.=I_{0}\right)$, IVF (mV), and chl, $a\left(\mathrm{mg} \mathrm{m}^{-3}\right)$ measured in the centre of a limnocorral ( $\boldsymbol{\Delta}$ indicates sampling).

\section{$\sim 40 \mu \mathrm{E} \mathrm{m}^{-2} \mathrm{~s}^{-1}$.}

The response of the IVF to rapid light fluctuations depends on the amplitude of the light intensity and the light conditions to which the algae were exposed before the onset of light fluctuations. Phosphate-limited Chlamydomonas cells were exposed to changing light intensities produced by a $1000 \mathrm{~W}$ tungsten halogen lamp (Figure 8). The transition from dark to light $\left(220 \mu \mathrm{E} \mathrm{m}^{-2} \mathrm{~s}^{-1}\right)$ caused a short $(1-2 \mathrm{~s})$ increase of the IVF followed by a rapid depression (phase a). Light fluctuations with a frequency of $0.1 \mathrm{~Hz}$ had a distinct effect on IVF (phase b). The amplitude of the IVF was smaller, when the amplitude of light intensity was changed from $0-220$ to $110-220$ and $160-220 \mu \mathrm{E}$ $\mathrm{m}^{-2} \mathrm{~s}^{-1}$, respectively (phase $\mathrm{c}$ ). The addition of DCMU increased light-induced IVF much more than dark IVF measurement, giving an apparent reversal pattern (phase d). The decay of the dark IVF in the presence of DCMU may be due to the back reaction between $\mathrm{Q}^{-}$and the primary oxidant $\mathrm{Z}^{+}$formed in the light (Bennoun, 1970).

Phytoplankton from $1 \mathrm{~m}$ depth, which were subjected to relatively high in situ light intensities, were sampled and immediately exposed to sunlight. The IVF of such lightadapted algae responded to changing light intensity. However, the response to fluctua- 


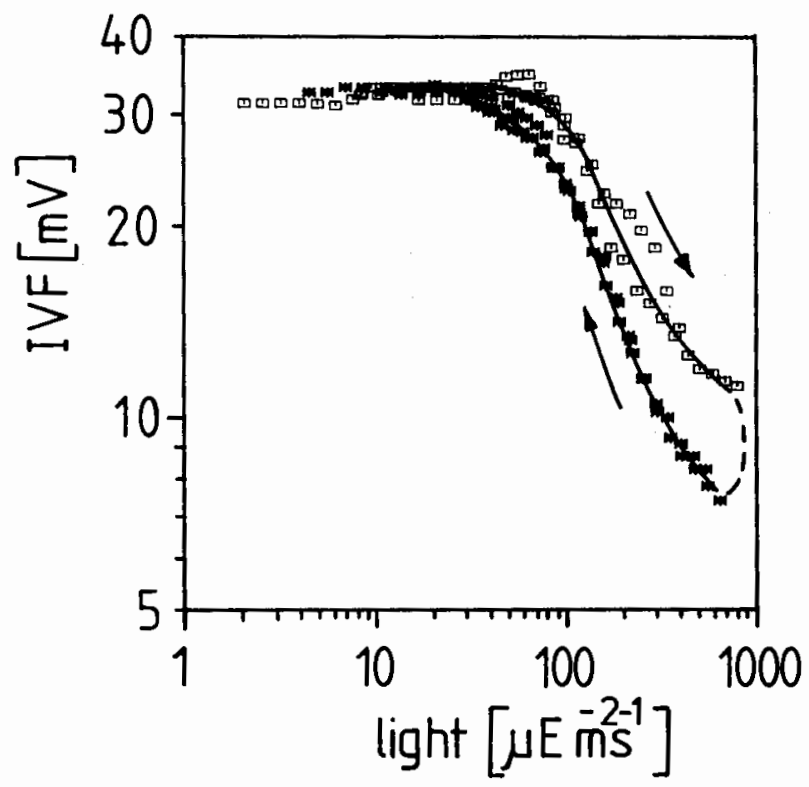

Fig. 7. IVF as a function of downwelling PAR (6 March 1984). Data from six profiles, $\square$ taken at $8,9,12$ a.m., *taken at $2,3,5$ p.m.

tions with a frequency of $0.1 \mathrm{~Hz}$ could hardly be distinguished from the noise of the signal (Figure 9a). After a dark phase of $2 \mathrm{~h}$, the plankton sample was again exposed to changing light. The IVF was now distinctly affected (at $0.1 \mathrm{~Hz}$ a decrease of $40 \%$ ) by the variations of the light intensity (Figure 9b), but 30 min later, the reaction of the IVF to light change had again diminished (Figure 9c).

\section{Discussion}

The crucial requirement for the interpretation of IVF measurements with regard to monitoring phytoplankton distribution in lakes is a constant relationship between IVF and chl. $a$ concentration. However, in agreement with other studies (Kiefer, 1973a; Loftus and Seliger, 1975), the ratio R between IVF and chl. $a$ was found to vary within the range 1.2-11.5 (Figure 4). This result is not surprising, as the biomass parameter, chl. $a$, is measured as a biological activity (IVF), which is linked with the extremely light-dependent process of photosynthesis. Amongst the factors influencing the variation of R, light is the most important, since in situ light changes occur much more rapidly than either changes in nutrient concentrations or algal growth. Based on the few diurnal investigations in Lake Lucerne, $R$ changed by a factor of up to 3 within one day. Moreover, light intensity varies widely within a few hours or even minutes, because flucutations in solar radiation caused by intermittent cloud cover, influence the IVF of phytoplankton. Data reported here show that IVF correlates negatively with changes in light intensity even at frequencies in the range of $0.1 \mathrm{~Hz}$. Furthermore, IVF changes show little lag when compared with changes in light intensity. The magnitude of the fast response is dependent on both the light conditions to which the phytoplankton 


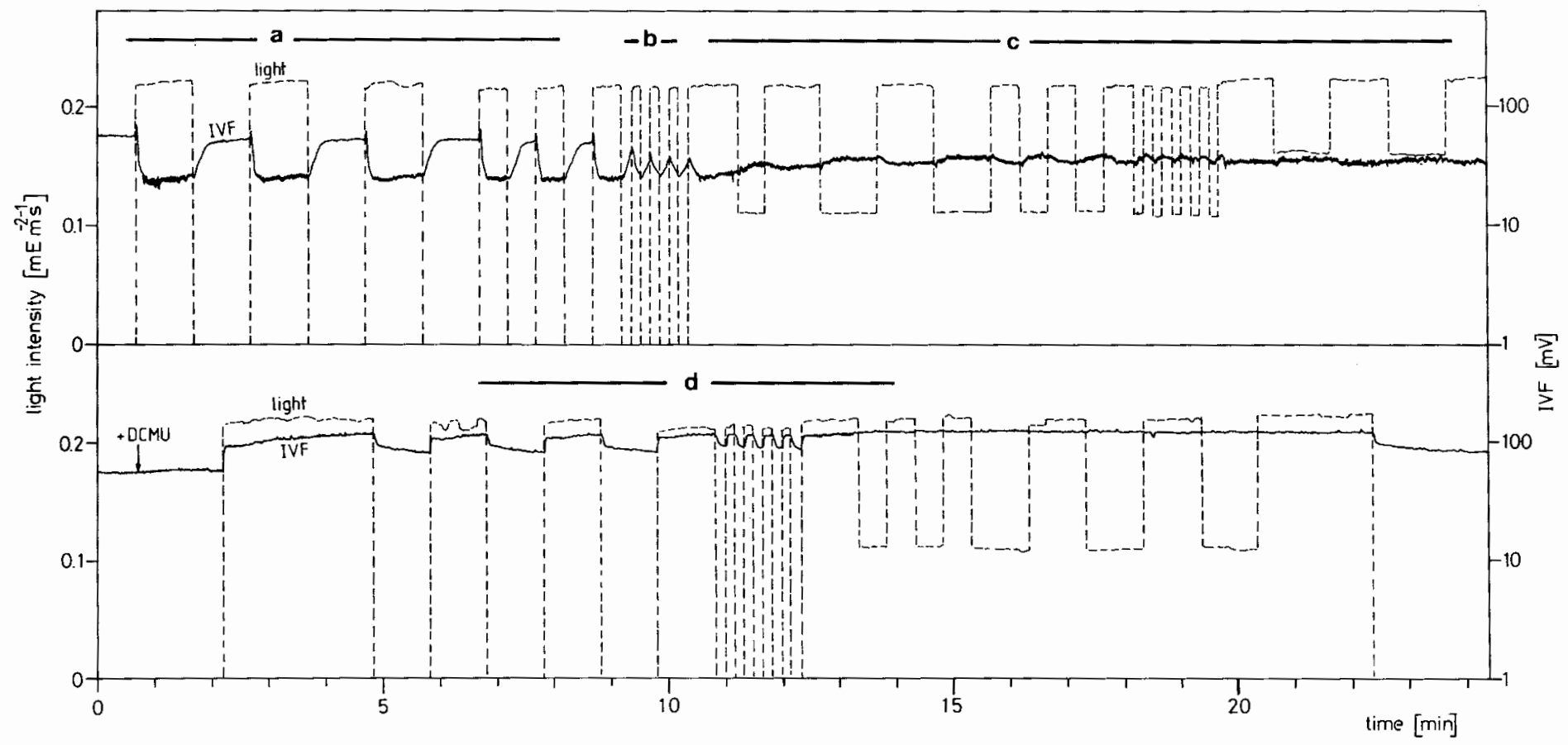

Fig. 8. Light and IVF chart record tracings of an experiment to measure the influence of intermittent illumination on the IVF of a diluted culture of Chlamydomonas. 


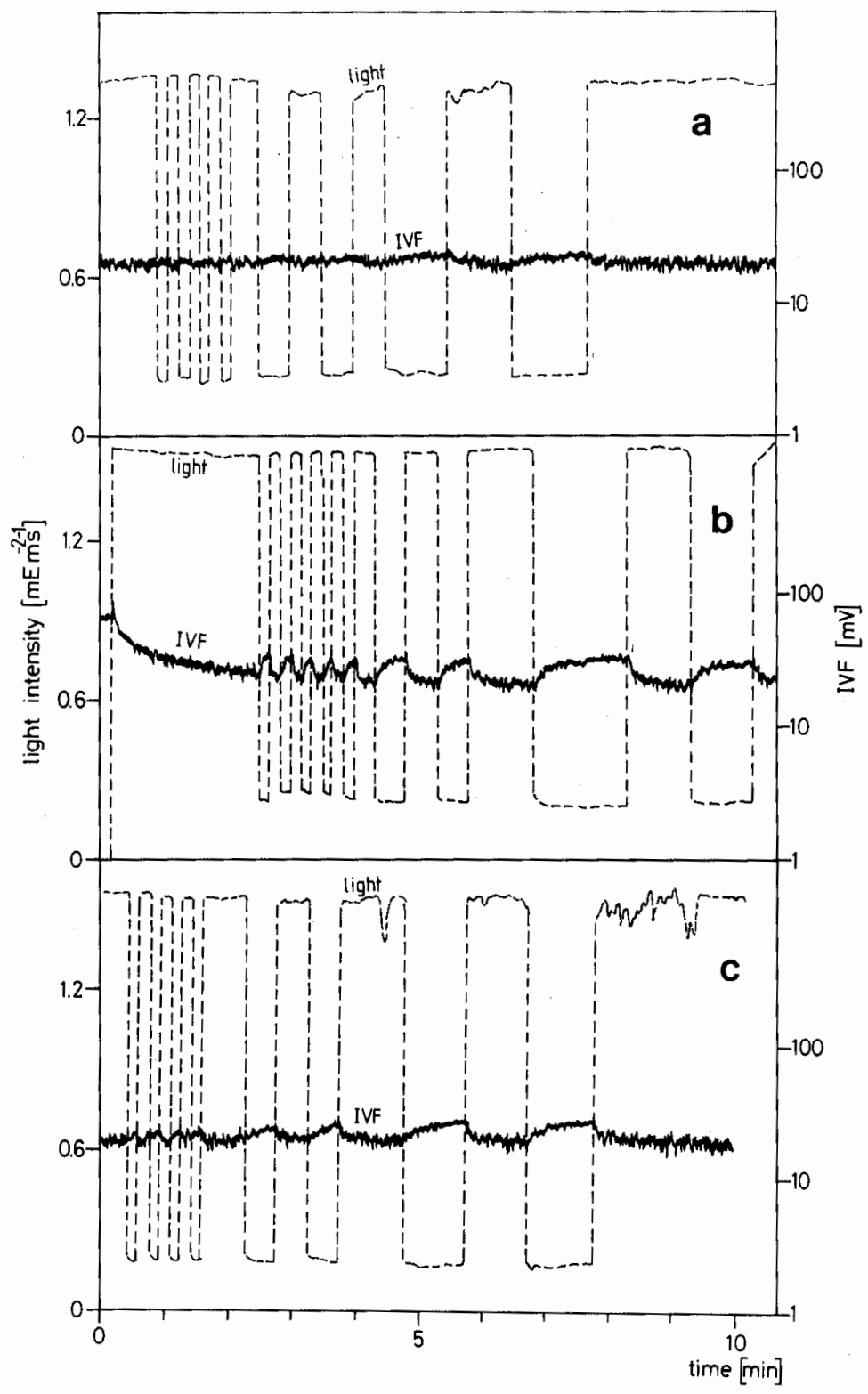

Fig. 9. Light and IVF chart record tracings of an experiment to measure the influence of intermittent iliumination on a natural phytoplankton population. (a) Population previously exposed to relatively high light intensity $\left(\sim 1250 \mu \mathrm{E} \mathrm{m}^{-2} \mathrm{~s}^{-1}\right)$, (b) immediately after a dark phase of $2 \mathrm{~h}$, (c) half an hour after the same dark phase.

has previously been exposed (Figure 9) and the relative change in light intensity (Figure 8). Both the magnitude and the time course of the fast response are also reported to be influenced by nutrient stress (Kiefer, 1973b). 


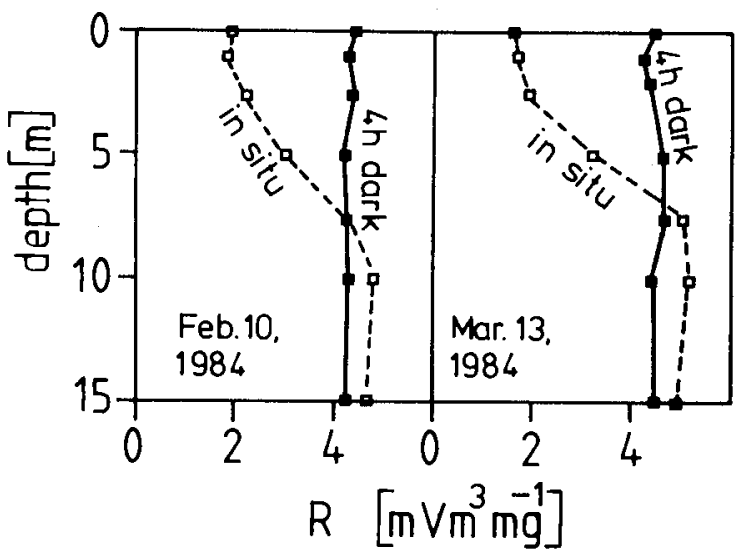

Fig. 10. R values obtained in situ and in the laboratory. $\square$ IVF measured in situ, $\square$ IVF measured after the samples have been stored in darkness for $4 \mathrm{~h}$.

The large variability in $\mathbf{R}$ necessitates a permanent calibration of the IVF against chl. $a$. However, direct measurement of chl. $a$ is time consuming. To optimize calibration, Slovacek and Hannan (1977) have suggested the measurement of the IVF after treatment with DCMU as they found that the IVF yield became a constant function of cellular chl. $a$. However, Prézelin and Ley (1980) showed that the IVF of DCMU poisoned cells was not constant and changed in direct proportion to photosynthesis. Our preliminary data indicate that light-induced variability of $\mathbf{R}$ within one profile can probably be eliminated by transferring the samples to darkness for $2-4 \mathrm{~h}$ before measuring the IVF (Figure 10). However, additional work in this connection is necessary.

In general, the methodological problems of the chlorophyll determination by measuring the IVF are the same for both pulse light and flow-through fluorometers. The phenomenon of photoinhibition is detectable, to a similar extent, with both instruments. However, their conceptual and operational differences may have an influence on IVF measurements. Since the mode of excitation in a pulse light fluorometer is much more intensive $\left(\sim 10^{4} \times\right)$ and shorter $\left(\sim 5 \times 10^{4} \times\right)$ than in a flow-through instrument, the fluorescence of the chl. $a$ in algae is likely to be affected in a different way. Since a direct comparison between the two systems has not been made, one can only speculate on the importance of this instrumental difference for IVF determinations and their corresponding interpretation. The pulse light fluorometer measures the IVF under ambient light conditions, whereas in a flow-through system the sample is removed from light to dark and therefore the effect of photoinhibition is decreased. However, as no pumps are required for the pulse light fluorometer, its measurements are faster, an advantage especially in monitoring programs.

\section{Acknowledgements}

I thank Dr. J.Bloesch and Dr. G.Hamer for the critical review of this manuscript, B.Germann and P.Wili for technical assistance in the field and in the laboratory. I appreciate chlorophyll data provided by Dr. H.Ambühl and E.Szabo. 


\section{References}

American Public Health Association (1975), Standard Methods for the Examination of Water and Wastewater, 14th ed., New York, 1032-1033.

Bennoun,P. (1970), Réoxydation du quencher der fluorescence 'Q' en présence de 3-(3,4-dichlorophényl)-1,2-diméthylurée, Biochim. Biophys. Acta, 216, 357-363.

Berman,T. (1972), Profiles of chlorophyll concentrations by in vivo fluorescence: some limnological applications, Limnol. Oceanogr., 17, 616-618.

Carison,R.E. and Shapiro,J. (1981), Dissolved humic substances: a major source of error in fluorometric analysis involving lake waters, Limnol. Oceanogr., 26, 785-790.

Früngel,F. and Koch,C. (1976), Practical experience with the Variosens equipment in measuring chlorophyll concentrations and fluorescent tracer substances, like rhodamine, fluorescein, and some new substances, IEEE J. Oceanic Eng., OE-1, 21-32.

Früngel,F. and Koch,C. (1980), A new in situ fluorometer for the measurement of fluorescent tracer substances with an exact logarithmic response over four decades, Meerestechnik, 11, 107-112.

Heaney, S.I. (1978), Some observations on the use of the in vivo fluorescence technique to determine chlorophyll $a$ in natural populations and cultures of freshwater phytoplankton, Freshwater Biol., 8, 115-126.

Herman,A.W. and Denman,K.L. (1977), Rapid underway profiling of chlorophyll with an in situ fluorometer mounted on a 'Batfish' vehicle, Deep-Sea Res., 24, 385-397.

Hirsbrunner,M. (1981), Chemostatanlage zur kontinuierlichen Kultur von Algen, Schweiz. Z. Hydrol., 43, 370-376.

Kiefer,D.A. (1973a), FLuorescence properties of natural phytoplankton populations, Mar. Biol., 22, 263-269.

Kiefer,D.A. (1973b), Chlorophyll $a$ fluorescence in marine centric diatoms: responses of chloroplasts to light and nutrient stress, Mar. Biol., 23, 39-46.

Loftus,M.E. and Seliger,H.H. (1975), Some limitations of the in vivo fluorescence technique, Chesapeake Sci, , 16, 79-92.

Lorenzen, C.J. (1966), A method for the continuous measurement of in vivo chlorophyll concentration, Deep-Sea Res., 13, 223-227.

Nusch,E.A. and Koppe,P. (198I), Temporal and spatial distribution of phytoplankton detected by in vivo et in situ fluorometry, Verh., Int. Ver. Theor. Angew. Limnol., 21, 756-762.

Prézelin,B.B. and Ley,A.C. (1980), Photosynthesis and chlorophyll $a$ fluorescence rhythms of marine phytoplankton, Mar. Biol., 55, 295-307.

SCOR/UNESCO (1969), Determination of photosynthetic pigments in sea-water, Monographs on Oceanographic Methodology, UNESCO, Paris, 1, 16-17.

Setser,P.J., Guinasso,N.L. and Schink,D.R. (1982), Daily patterns of fluorescence in vivo in the central equatorial Pacific, J. Mar. Res., 40, 453-47I.

Slovacek,R.E. and Hannan,P.J. (1977), In vivo fluorescence determinations of phytoplankton chlorophyll a, Limnol. Oceanogr., 22, 919-925.

Smith,V.H. (1983), Light and nutrient dependence of photosynthesis by algae, J. Phycol., 19, 306-313.

Staub,R. (1961), Ernährungsphysiologisch-autökologische Untersuchungen an der planktischen Blaualge Oscillatoria rubescens, D.C., Schweiz. Z. Hydrol., 23, 82-198.

Uehlinger,U., Bossard,P., Bloesch,J., Bürgi,H.R. and Bührer,H. (1984), Ecological experiments in limnocorrals: methodological problems and quantification of the epilimnetic phosphorus and carbon cycles, Verh., Int. Ver. Theor. Angew. Limnol, 22, 163-171.

Received June 1984; accepted December 1984 